\title{
Competitive Metal lon Binding to Datura innoxia Root and Stem Tissue Materials
}

\begin{abstract}
Keywords: Datura innoxia; Metal ions; Biosorption; Affinities Abstract

Dried root and stem tissue samples from the plant, Datura innoxia, were exposed to solutions containing six metal ions, $\mathrm{Zn}^{2+}, \mathrm{Cu}^{2+}, \mathrm{Cd}^{2+}, \mathrm{Ni}^{2+}, \mathrm{Pb}^{2+}$ and $\mathrm{Eu}^{3+}$. The resulting binding isotherms were generated using multiline atomic emission spectra of supernatant solutions. Application of regularized regression analysis to these isotherms revealed binding sites exhibiting both low and high value conditional affinities. Low affinity sites $\left(1.5 \times 10^{-2}\right.$ to $\left.2.5 \times 10^{-1}\right)$ were postulated to involve electrostatic physisorption processes with large potential capacities $(0.11$ to 3.2 moles gram $^{-1}$. These involved $\mathrm{Cd}^{2+}, \mathrm{Cu}^{2+}, \mathrm{Ni}^{2+}, \mathrm{Pb}^{2+}$ and $\mathrm{Zn}^{2+}$ ions. High affinity sites revealed conditional constants varying from $2.5 \times 10^{2}$ to $1.3 \times 10^{9}$ with potential capacities of $12 \mu$ moles $\mathrm{g}^{-1}$ to $0.15 \mathrm{moleg}^{-1}$. These were attributed to surface complex formation and included each metal ion studied. This is the first reporting of relative affinities and capacities for metal ion biosorption under competitive conditions involving seven metals. Similarities in measured affinity constants for each metal when comparing root and stem tissue materials suggest similar predominate chemical interactions involving either of these binding mechanisms. These results support mechanisms involving carboxylates for both root and stems materials. Site densities clearly show the vast majority of binding interactions to be governed by more general electrostatic forces. Such would be advantageous for the application of this plant for phytoextraction purposes.
\end{abstract}

\section{Introduction}

Phytoextraction involves plants for hazardous material removal from polluted soil or water [1]. Typically, this involves heavy metal ion sequestration and transport [2]. Use of plants can enable cost-effective remediation of large-volume contaminated soil or water. Realization of that potential, however, requires understanding those chemical interactions involved [3]. Significant progress continues toward elucidation of chemical processes responsible for phytoextraction interactions [4-15]. These include: metal-ion surface complex formation with tissue functional groups [8-16]; ion-exchange interactions [10-15]; and electrostatic (Coulombic) attraction of metal cations with a net negatively charged plant material [13-15,17]. These interactions can be distinguished by decreasing interaction strength and associate affinities $[6,15,17]$.

Past studies of phytoextraction have utilized an arsenal of techniques to understand metal-ion/biomaterial interactions. These included x-ray [7], infrared [18], and metal luminescence spectroscopy $[6,15,19]$, chromatographic techniques $[8,20]$, and binding isotherm data analysis and simulation [5]. Those studies revealed oxy-anion involvement, typically as carboxylates, in the biosorption of a variety of metal ion species [7,9] on non-viable biomaterials ranging in biocomplexity from single-cell algae to intact plant tissues [5,6-9,13-15].

Analysis of binding isotherms has also yielded fundamental thermodynamic parameters governing such interactions [15,21]. In

\section{Analytical \& Molecular Techniques}

\author{
Richie Eriacho ${ }^{1}$, Ryan C. Carn², Jessica L. Moore ${ }^{3}$ \\ and Gary D. Rayson ${ }^{4^{*}}$ \\ ${ }^{\prime}$ Department of Chemistry, State University of New York, Buffalo, \\ New York, USA \\ ${ }^{2}$ Kirkland Airforce Base, Albuquerque, NM 87117, USA \\ ${ }^{3}$ Department of Chemistry, University of California at Davis, Davis, \\ CA 95616, USA \\ ${ }^{4}$ Department of Chemistry and Biochemistry, New Mexico State \\ University, Las Cruces, NM 88003, USA
}

\section{Address for Correspondence}

Gary D. Rayson, Department of Chemistry and Biochemistry, New Mexico State University, Las Cruces, Box 30001 MSC 3C, NM 88003, USA, E-mail: gdrayson@nmsu.edu

Submission: 24 March, 2016

Accepted: 30 April, 2016

Published: 05 May, 2016

Copyright: (c) 2016 Eriacho R, et al. This is an open access article distributed under the Creative Commons Attribution License, which permits unrestricted use, distribution, and reproduction in any medium, provided the original work is properly cited.

Reviewed \& Approved by: Dr. Huan-Tsung Chang, Department of Chemistry, National Taiwan University, Taiwan

those studies, metal ion binding was reported to exhibit Langmuirian behavior at low concentrations $[13,14]$ while adhering to a Freundlich binding model under conditions of higher concentration [13]. Conditional affinity constant elucidation enabled calculation of Gibb's free energy changes associated with single metal-ion total binding to plant biomaterials (i.e. $\Delta \mathrm{G}$ ) $[13,14,17]$. Generally, these calculations supported a thermodynamically favorable sorption process (i.e. $\Delta G<0)$ [13]. However, a positive $\Delta G$ has been also reported for specific metal ion/biosorbent combinations at room temperature [13]. These thermodynamically unfavorable parameters were explained as indicative of additional processes influencing metal ion biosorption [13]. More recently, variation in binding temperature conditions further enabled extraction of both $\Delta \mathrm{H}$ and $\Delta \mathrm{S}$ values for binding of $\mathrm{Eu}(\mathrm{III})$ to root and stem tissues from Datura innoxia [17]. That study reported metal sorption to Datura innoxia root and stem materials as both endothermic $(\Delta \mathrm{H}>0)$ and entropically driven (i.e. $\Delta S>0)$. This is consistent with values reported by Bertoni et al. for $\mathrm{Mo}(\mathrm{VI})$ binding to a green seaweed biomass [18].

Unfortunately, many of these past studies were restricted to single metal-ion exposure conditions [4-15,18]. The potential impact of competitive metal ion binding to specific sites was not addressed in those earlier studies. The present study investigated metal ion biosorption within solutions containing each of seven (7) metal ions and the resulting binding isotherms for root and stem materials from D. innoxia. Specifically, biosorption of $\mathrm{Cu}^{2+}, \mathrm{Cd}^{2+}, \mathrm{Ni}^{2+}, \mathrm{Zn}^{2+}, \mathrm{Pb}^{2+}$, and $\mathrm{Eu}^{3+}$ was investigated. These metal ions were selected based on earlier studies in our laboratory involving sequential exposure to biosorbent materials derived from cultured tissues of the same plant species $(\mathrm{Cd}$, $\mathrm{Ni}, \mathrm{Zn}$ ) [21] and simultaneous exposure in a flowing system [20] to 
Citation: Eriacho R, Carn RC, Moore JL, Rayson GD. Competitive Metal Ion Binding to Datura innoxia Root and Stem Tissue Materials. J Analyt Molecul Tech 2016;2(1): 6.

ISSN: $2474-1914$

Table 1: Emission wavelengths used for each metal with the corresponding sensitivity (slope of the working curve), $y$-intercept, and coefficient of determination, $\mathrm{r}^{2}$ The order of diffraction associated with a wavelength is provided.

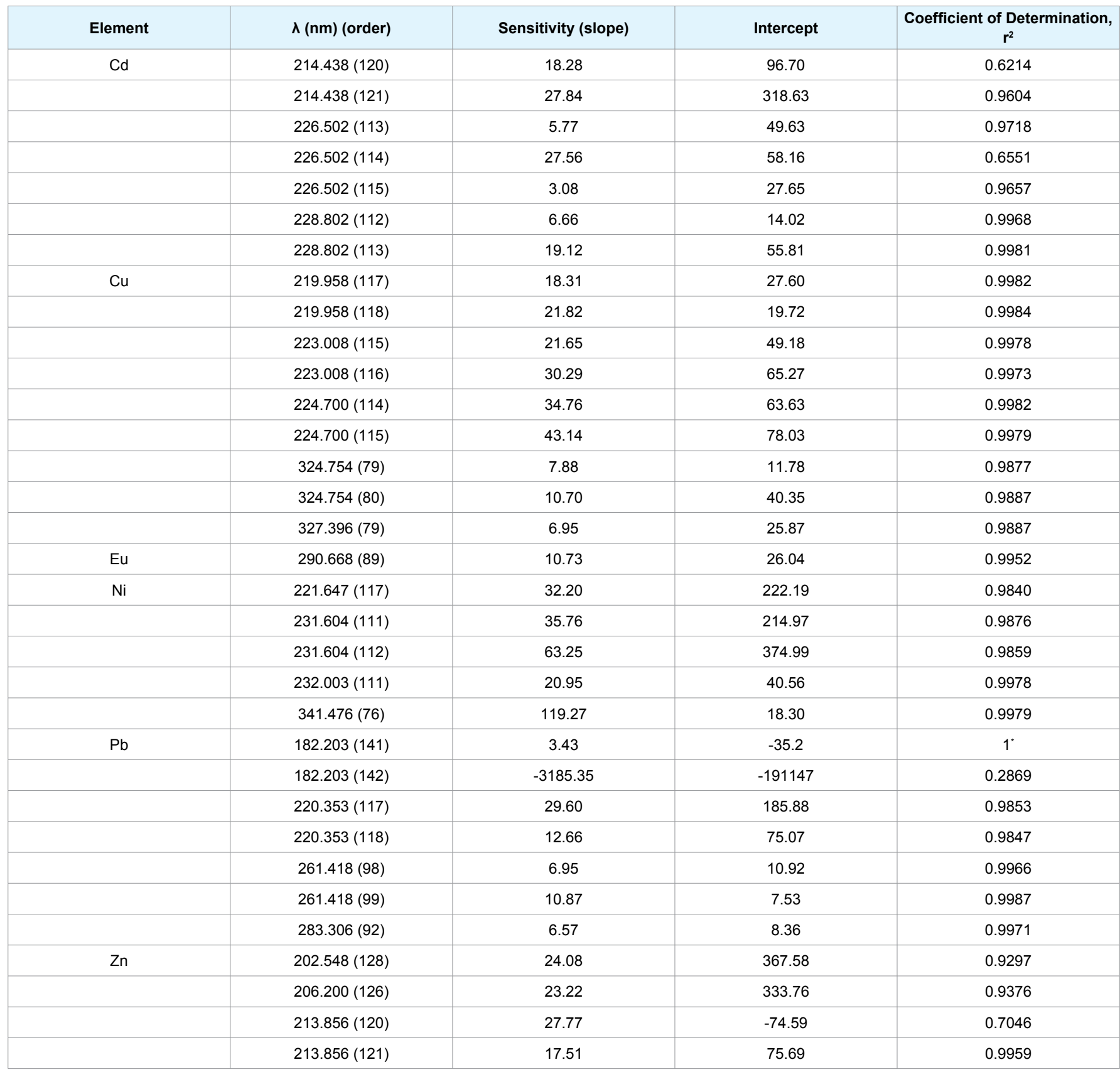

*Only two concentrations resulted in values significantly different from the blank measurement. These measurements were omitted from further analysis.

address potential metal ion exchange processes. Eu(III) was included because of its chemical similarity to Am(III) [22,23] and its extensive investigation within our laboratory (e.g. $[6,9,15])$. D. innoxia was selected because of several favorable characteristics pertaining to potential use in phytoextraction applications (e.g. a heavy metal resistant perennial plant that is native to arid environments and naturally resistant to herbivory) [24]. Root and stem materials were investigated in the present study because of their potential involvement in transport of metal ions from contaminated soil to the shoots and leaves of the plant [25].
Application of regularized regression analysis [26-28] to each isotherm generated a corresponding affinity spectrum of site density as a function of the conditional affinity constant, $\mathrm{K}_{c}$, for each binding environment $[8,15]$. Distributions of these conditional affinity constants, specifically $\log \mathrm{K}_{\mathrm{c}}$, facilitate discernment of dominate general metal-ion binding mechanism elucidation (e.g. electrostatic attraction or surface complex formation) based on the relative magnitudes of $K_{c}[8,15]$ under these competitive binding exposure conditions. 
Table 2: Calculated conditional affinity constants for each metal ion bound to root and stem materials from Datura innoxia using various atomic emission wavelengths with respective binding site densities.

\begin{tabular}{|c|c|c|c|c|c|c|c|c|c|}
\hline \multirow{4}{*}{$\begin{array}{c}\text { Metal ion } \\
\text { Cd }\end{array}$} & \multirow{4}{*}{$\begin{array}{c}\text { Wavelength (nm) } \\
214.438\end{array}$} & \multicolumn{4}{|c|}{$\log K_{c}$} & \multicolumn{4}{|c|}{ Site Densities, mole/gram } \\
\hline & & \multirow{2}{*}{\multicolumn{2}{|c|}{$\begin{array}{l}\text { Stems } \\
\text { low high }\end{array}$}} & \multirow{2}{*}{\multicolumn{2}{|c|}{$\begin{array}{l}\text { Roots } \\
\text { low high }\end{array}$}} & \multicolumn{2}{|c|}{ Stems } & \multicolumn{2}{|c|}{ Roots } \\
\hline & & & & & & \multicolumn{2}{|c|}{ low high } & low & high \\
\hline & & -0.6 & 5.0 & -0.58 & 5.13 & 0.109 & $2.31 \times 10^{-5}$ & 0.128 & $1.75 \times 10^{-5}$ \\
\hline & 226.502 & -0.8 & 4.8 & -0.81 & 4.67 & 0.293 & $3.19 \times 10^{-5}$ & 0.253 & $2.12 \times 10^{-5}$ \\
\hline & 228.802 & -0.9 & 4.4 & -0.81 & 4.21 & 0.292 & $3.61 \times 10^{-5}$ & 0.255 & $2.58 \times 10^{-5}$ \\
\hline \multirow{2}{*}{$\mathrm{Cu}$} & 219.958 & -1.2 & 3.4 & -1.23 & 3.3 & 1.073 & $1.23 \times 10^{-4}$ & 0.901 & $9.18 \times 10^{-5}$ \\
\hline & 324.754 & ND & 2.4 & ND & 2.6 & ND & $1.35 \times 10^{-3}$ & ND & $2.07 \times 10^{-3}$ \\
\hline \multirow{4}{*}{$\mathrm{Ni}$} & 221.647 & -1.1 & 3.9 & -1.3 & 4.4 & 1.173 & $3.24 \times 10^{-5}$ & 1.139 & $1.51 \times 10^{-5}$ \\
\hline & 231.604 & -1.4 & ND & -1.2 & 3.8 & 3.199 & ND & 0.857 & $2.40 \times 10^{5}$ \\
\hline & 232.003 & -1.3 & 3.4 & -1.5 & 3.3 & 1.170 & $7.25 \times 10^{-5}$ & 0.933 & $4.63 \times 10^{-5}$ \\
\hline & 341.476 & -1.4 & 2.8 & -1.3 & 2.5 & 1.13 & $1.8 \times 10^{-4}$ & 0.845 & $1.69 \times 10^{-4}$ \\
\hline $\mathrm{Eu}$ & 290.668 & ND & 3.1 & -0.06 & 6.57 & ND & 0.00116 & 0.0229 & 0.00830 \\
\hline $\mathrm{Pb}$ & 182.203 & -1.6 & ND & -1.5 & ND & 2.233 & ND & 1.652 & ND \\
\hline \multirow{3}{*}{$\mathrm{Zn}$} & 202.548 & -1.5 & 4.4 & -1.4 & 1.36 & 1.322 & $8.07 \times 10^{-5}$ & 1.360 & 0.0148 \\
\hline & 206.200 & -1.3 & 4.1 & -1.5 & 4.7 & 1.723 & $1.31 \times 10^{-4}$ & 1.587 & $1.54 \times 10^{-4}$ \\
\hline & 213.856 & -1.5 & 3.2 & -1.8 & 3.7 & 0.699 & $3.00 \times 10^{-4}$ & 2.521 & $5.85 \times 10^{-5}$ \\
\hline
\end{tabular}

ND indicates binding sites were not indicated using linearized regression analysis of corresponding isotherm data.

\section{Materials and Methods}

Multi-element solutions containing $1,5,10,50$, and $100 \mu \mathrm{g} \mathrm{mL}^{-1}$ of $\mathrm{Cu}^{2+}, \mathrm{Cd}^{2+}, \mathrm{Ni}^{2+}, \mathrm{Zn}^{2+}, \mathrm{Pb}^{2+}$, and $\mathrm{Eu}^{3+}$ were prepared from $1000 \mu \mathrm{g}$ $\mathrm{mL}^{-1}$ stock solutions of each metal. Each was obtained by dissolution of the corresponding nitrate salt with the exception of $\mathrm{Eu}(\mathrm{III})$ which was generated by dissolution of $\mathrm{Eu}_{2} \mathrm{O}_{3}$ in a minimal amount of concentrated $\mathrm{HNO}_{3}$ [15]. All solutions were adjusted to a $\mathrm{pH}$ of 5 through the drop wise addition of either concentrated $\mathrm{HNO}_{3}$ or saturated $\mathrm{NaOH}$. These concentrations were used as representative of environmentally relevant amounts [20].

Root and stem tissue materials from $D$. innoxia were prepared as described elsewhere [17]. Briefly, this involved collection of $D$. innoxia plants from a dry arroyo area on the campus of New Mexico State University in Las Cruces, NM. Following separation of plant components (i.e. roots, stems, leaves, flowers, and seeds), the tissues were dried overnight at $60^{\circ} \mathrm{C}$, ground in a commercial blender (Oster, model Osterizer) and sieved. The 100-200 mesh fraction was collected and washed in $1.0 \mathrm{M} \mathrm{HCl}$ to remove endogenous metal ions [20]. These materials were then freeze-dried and stored.

Both samples and controls were generated in triplicate for each metal ion concentration with corresponding blanks (i.e. no added metal ions). Samples consisted of $30 \mathrm{mg}$ of either root or stem materials added to a $3 \mathrm{~mL}$ test tube. A $2.5 \mathrm{~mL}$ aliquot of the corresponding metal containing solution was then added to each sample and agitated for 20 minutes on a rocker (model Labquake). These were subsequently centrifuged (Sorval, model GLC-2B) for 20 minutes at $3000 \mathrm{rpm}$. The resulting supernatant was then analyzed using an inductively coupled plasma optical emission spectrometer equipped with a charge injection device (CID) detector (Thermo Fischer, IRIS). This results in a two-dimensional matrix of emission intensity for each wavelength (columns) with varied orders of diffraction (rows). Images of these emission spectra from 176.752 to $346.139 \mathrm{~nm}$ (at diffraction orders of 74 to 144) were collected for each sample and stored for later analysis. Consequently, selection of wavelengths for each element could be undertaken post analysis. Control samples were prepared and analyzed identically except for the absence of the biomaterial. All samples were collected under equilibrium conditions to investigate binding under static conditions to better understand relative metal affinities to these two tissues.

Storage of the entire spectral image enabled post-analysis selection and processing of emission wavelength intensities for each element for maximum effective dynamic range. Table 1 list the wavelengths used for each metal. Selection of multiple transitions with varied sensitivities enabled an extension of the effective dynamic range for each metal and investigation of metal binding under various concentration range conditions [17] as opposed to more conventional selection of a single wavelength for each metal. Calibration of each metal at the respective wavelengths was accomplished using multielement standard solutions containing $1,5,10,50$ and $100 \mu \mathrm{g} \mathrm{mL}^{-1}$ of each metal ion. The resulting slope, intercept, and coefficient of determination, $\mathrm{r}^{2}$, for each emission wavelength is also listed in Table 1. Subsequent determinations then used a combination of these wavelengths. Wavelengths that yielded values of $\mathrm{r}^{2}<0.9$ were deselected from further consideration. Intensities that were not significantly different than the blank were also omitted. The regression line slopes indicate the experimental sensitivity observed for each wavelength under these operating conditions (1350 W RF power, $15 \mathrm{~L} \mathrm{~min}^{-1}$ outer flow, $1.0 \mathrm{~L} \mathrm{~min}^{-1}$ nebulizer gas flow, and $1.0 \mathrm{~mL} \mathrm{~min}{ }^{-1}$ solution flow). It should be noted sensitivities listed are relative values for comparison within the present study and should not be related to literature values reported for these wavelengths.

\section{Results and Discussion}

Binding isotherms for each metal were generated by calculation of $\mathrm{q}$, the amount of metal ion bound to the biosorbent, using mass balance criteria. 

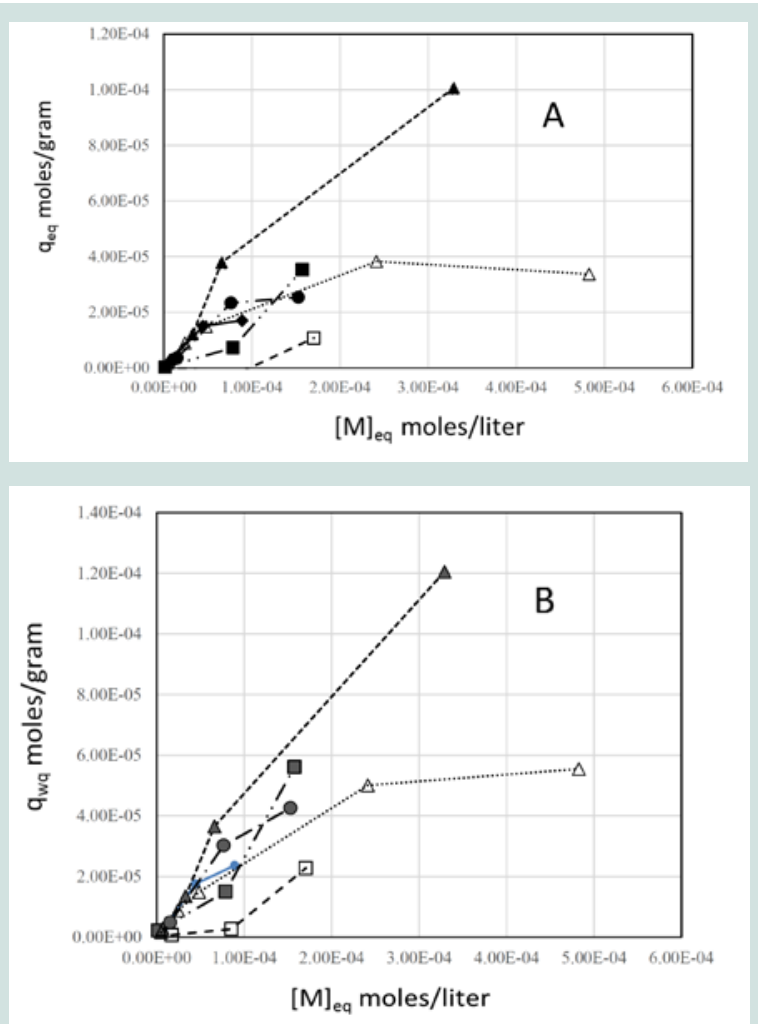

Figure 1: Metal ion binding isotherms at room temperature $\left(\sim 25^{\circ} \mathrm{C}\right)$ to dried Datura innoxia tissues from (A) roots and (B) stems for $(\triangle$. $) \mathrm{Pb}^{2+}$, $\mathrm{Cu}^{2+},(\bullet \bullet.) \mathrm{Zn}^{2+},($ 므__ $) \mathrm{Ni}^{i^{2+}},(-\boldsymbol{\Lambda}-) \mathrm{Eu}^{3+}$.

$$
q=\frac{[M]_{\text {control }} V_{\text {control }}-[M]_{\text {sample }} V_{\text {sample }}}{m_{\text {biosorbent }}}
$$

Where the variables, $[\mathrm{M}]_{\text {control }}$ and $[\mathrm{M}]_{\text {sample' }}$ represent the calculated metal ion concentrations in the control and samples in moles per liter, respectively. Similarly, $\mathrm{V}_{\text {control }}$ and $\mathrm{V}_{\text {sample }}$ denote the corresponding solution volumes in liters. The variable $\mathrm{m}_{\text {bioxorbent }}$ is the mass of biosorbent in grams. Figure 1 shows representative isotherms for $\mathrm{Eu}, \mathrm{Pb}, \mathrm{Cd}, \mathrm{Cu}, \mathrm{Ni}$, and $\mathrm{Zn}$ ions for root and stem materials (Figures $1 \mathrm{~A}$ and $1 \mathrm{~B}$, respectively). While some metal ions exhibited the more typical plateau region at higher concentrations for each material (e.g. $\left.\mathrm{Pb}^{2+}, \mathrm{Zn}^{2+}, \mathrm{Cd}^{2+}\right)$, other metal ions showed increasing binding under similar conditions (e.g. $\mathrm{Eu}^{3+}, \mathrm{Cu}^{2+}$, and $\mathrm{Ni}^{2+}$ ).

Because of the inherent chemical heterogeneity of plant-based biosorbents [19], a binding model first proposed by Sips [29] was used to analyze these binding isotherms.

$$
q=\frac{M\left(K_{c} C\right)^{\beta}}{1+\left(K_{c} C\right)^{\beta}}
$$

Where $\mathrm{q}$ represents the amount adsorbed, $\mathrm{M}$ the maximum adsorption, and $\mathrm{C}$ the adsorbate's equilibrium concentration [29]. $\mathrm{K}_{c}$ represents the conditional equilibrium constant and $\beta$ is the LangmuirFreundlich coefficient [29]. Non-linear regression is typically used to fit data to this three parameter model $\left(M, K_{c}, \beta\right)$ and exhibits the form:

$$
q(c)=\int_{\Delta} \frac{K_{c}}{1+K_{c}} f\left(\log K_{c}\right) d \log K_{c}
$$

$\mathrm{q}(\mathrm{c})$ is the total material adsorbed with solution concentration, $c$, and continuous variation in conditional affinity constant, $\mathrm{K}_{\mathrm{c}}$, and affinity distribution of $\mathrm{f}\left(\log \mathrm{K}_{\mathrm{c}}\right)=\mathrm{S}_{\mathrm{i}} / \Delta$, where $\Delta=\log \mathrm{K}_{\mathrm{c}, \mathrm{i}+1}-\log \mathrm{K}_{\mathrm{c}, \mathrm{i}}$ depicts the grid spacing. The inverse solution of equation 2 yields the density of binding sites, $S_{i}$, as a function of log K. Solution of this ill-posed problem was first reported in Sip's landmark paper for heterogeneous surfaces [29] and determined using regularized least-squares methods, as described by Černik et al. [28]. Because of the conditional nature of the affinities, the resulting distributions of site densities have been more recently described by Gracés et al. as conditional affinity spectra (CAS, equation 2) [26-28]. Binding occurs at individual sites which exhibit a continuum of affinity constants, $\mathrm{K}_{c}$. In reality, conditional constant, $\mathrm{K}_{\mathrm{c}}$, is computed for metal ion binding under defined conditions of solution $\mathrm{pH}$ and ionic strength [27].

Application of regularized regression analysis enables computation of a numerical solution to this equation for $\log \mathrm{K}_{c}$. This generates affinity spectra of site densities as a function of $\log \mathrm{K}_{c}$ [27]. These are illustrated in Figure 2 for the respective isotherms in Figure 1. A limitation of this approach is its dependence on limits of detection and linear dynamic ranges of the method used for metal ion quantitation. An inability to measure low concentrations can negatively impact the discernment of low-density, high affinity sites which would be saturated in the presence of small amounts of a metal ion. Conversely, a limited dynamic range may obscure elucidation of interactions exhibiting extremely low apparent affinities [20,21]. Using selected emission wavelengths demonstrating a range of sensitivities allows each limitation to be addressed. Additionally, 


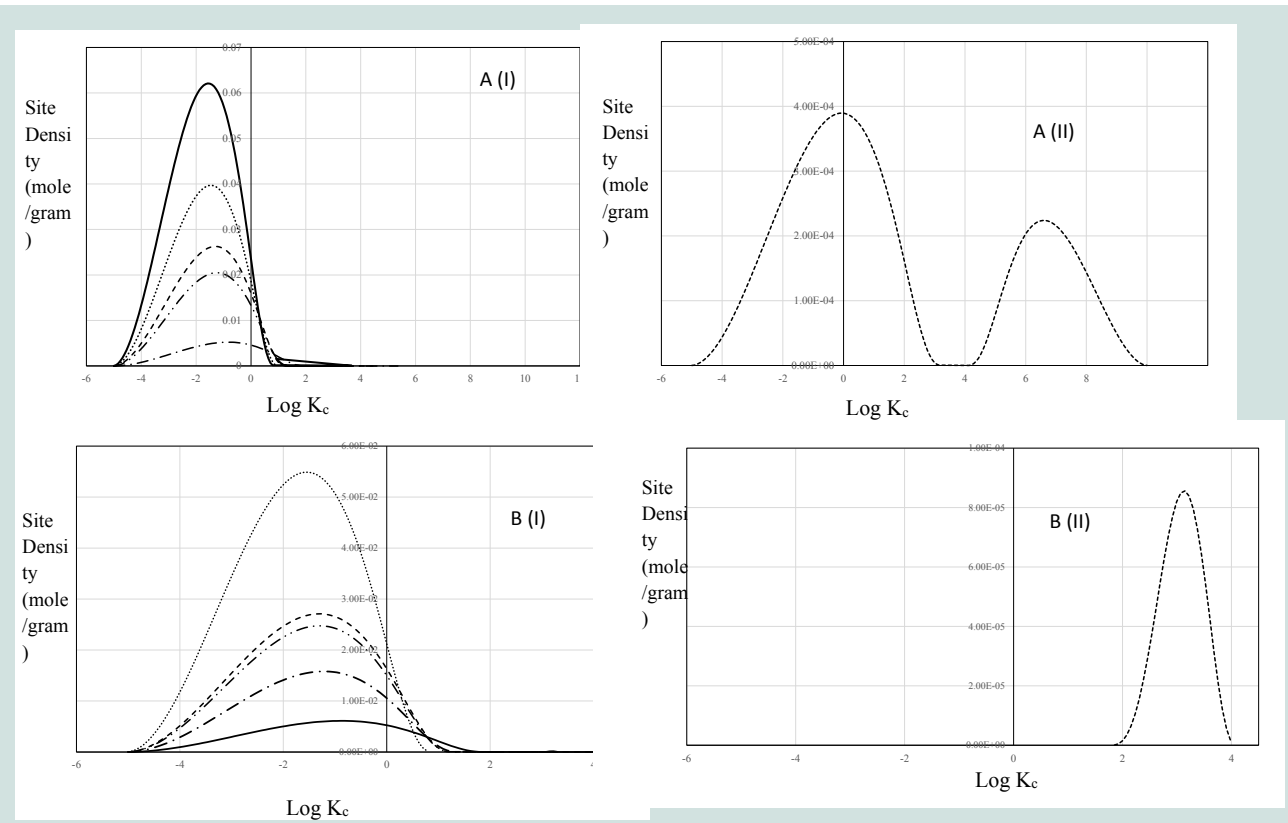

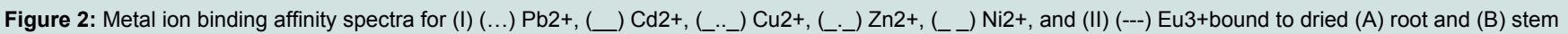
tissues form $D$. innoxia.

sample-to-sample variations in measured parameters (e.g. metal ion concentrations in control and supernatant solutions) can be minimizing (or eliminating) by this approach. This is compared to more typical methods involving dilution of multi-element solutions to accommodate single element sensitivities when employing single emission wavelengths.

Table 2 lists the integrated site densities (i.e. peak areas) and conditional affinity constants, as $\log \mathrm{K}_{c}$ (i.e. peak location) for each wavelength of each metal for the different tissue types studied (i.e. root and stem materials). Readily apparent from these results is the predominance of a collection of sites exhibiting a mean $\log \mathrm{K}_{\mathrm{c}}$ values of -1 and about 4 (Figure 2). Earlier studies in our laboratory of single metal ion binding to a similar biosorbent proposed sites with $\log \mathrm{K}_{\mathrm{c}}=-$ 1 to result from either an electrostatic attraction of the metal cations to a net negatively charged material or a weak ion-exchange mechanism $[8,15]$. Such an explanation is also consistent with the presence of a "common" (i.e. metal-independent) binding site proposed by Williams and Rayson for sequential metal ion exposure [20,21]. An electrostatic attraction mechanism is further supported by the larger

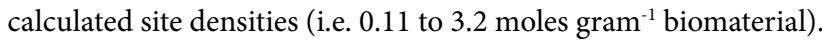

In addition to these proposed "common" sites are the various high affinity sites listed in Table 2 (and Figures 2A2 and 2B2). Generally, both root and stem materials exhibited $\log \mathrm{K}_{c}$ values of 2.4 to 4.8 $(\mathrm{Cu}$ at $324.7 \mathrm{~nm}$ to $\mathrm{Cd}$ at $226.5 \mathrm{~nm}$, respectively). In contrast, $\mathrm{Pb}$ yielded sites with $\log K_{c}$ values of 2.5 and 9.1 (observed at $\lambda=220.3$ $\mathrm{nm})$. In comparison, the majority of these high affinity sites exhibit site densities of approximately $10^{-5} \mathrm{~mol} \mathrm{~g}^{-1}$ while $\mathrm{Pb}$ and Eu revealed densities two to three orders-of-magnitude larger than other metal ions at similar sites.

Such an increased affinity and capacity for $\mathrm{Pb}$ is consistent with earlier reported studies involving simultaneous exposure of anther cell-derived material to a similar collection of metal ions [20-21].
The observation of only high-affinity sites for Eu(III) binding is also consistent with earlier reports by Serna et al. [15] in which multiple classes of sites were discerned based on both functional groups involved and associated conditional affinities [15].

\section{Conclusions}

Physisorption of metal ions to both root and stem tissues from D.innoxia due to electrostatic attraction is indicated as the dominate mechanism for passive biosorption of $\mathrm{Cd}^{2+}, \mathrm{Cu}^{2+}, \mathrm{Ni}^{2+}, \mathrm{Pb}^{2+}$, and $\mathrm{Zn}^{2+}$ ions. These sites are characterized by low conditional affinity constants of $1.5 \times 10^{-2}$ to $2.5 \times 10^{-1}$ and high site densities (i.e. potential binding capacities) of 0.11 to 3.2 moles $\mathrm{g}^{-1}$ of the dry biosorbent. This suggests a potential mechanism for transport of these metal ions through the plant once extracted into the roots.

Each material also exhibited relatively high affinity sites for each metal ion with potential capacities of micromoles per gram dried tissue. The magnitude of these associated condition affinity constants $\left(10^{4}\right.$ to $\left.10^{9}\right)$ suggests the involvement of surface metal ion complexes [8-9]. This further suggests the potential for greater retention of these metal ions by both root and stem tissues. Interestingly, the conditional affinity constants for $\mathrm{Eu}(\mathrm{III})$ binding from these metal in these mixtures were relatively high $\left(2.5 \times 10^{2}\right.$ and $1.5 \times 10^{9}$ for roots and stem, respectively, Figures $2 \mathrm{~A}$ and $2 \mathrm{~B}$ II) with potential capacities of 0.12-150 millimole metal ion per gram dry tissue. Similarities in measured affinity constants for each metal when comparing the two tissue materials suggest similar predominate chemical interactions involving either low-affinity electrostatic biding or formation of surface-metal complex formation. Previous studies in our laboratory have indicated carboxylate functionalities associated with those sites (e.g. $\mathrm{Cd}^{2+}[6], \mathrm{Pb}^{2+}[8]$, and $\mathrm{Eu}^{3+}[9]$ ). These results support a similar mechanism for both root and stems materials. Site densities clearly show the vast majority of binding interactions to be governed by 
Citation: Eriacho R, Carn RC, Moore JL, Rayson GD. Competitive Metal Ion Binding to Datura innoxia Root and Stem Tissue Materials. J Analyt Molecul Tech 2016;2(1): 6.

more general electrostatic forces. Such would be advantageous for the application of this plant for phytoextraction purposes. These results would then suggest the potential ability of these plant tissues to extract this trivalent metal ion more efficiently then the concomitant divalent ions, but its mobility through the plant may be less efficient as it is more tightly bound to each site.

\section{Disclaimer}

Any opinions, findings, conclusions or recommendations expressed in this paper are those of the authors and do not necessarily reflect the views of the National Science Foundation.

\section{References}

1. Sas-Nowosielska A, Kucharski R, Pogrzeba M, Malkowski E (2008) Soil remediation scenarios for heavy metal contaminated soil. Soil Chemical Pollution, Risk Assessment, Remediation and Security: 301-307.

2. Kumar PB, Dushenkov V, Motto H, Raskin I (1995) Phytoextraction: the use of plants to remove heavy metals from soils. Environ Sci Technol 29: 1232 1238.

3. Doran PM (2009) Application of plant tissue cultures in phytoremediation research: incentives and limitations. Biotechnol Bioeng 103: 60-76.

4. Igwe JC, Abia AA (2007) Equilibrium sorption isotherm studies of Cd(II), $\mathrm{Pb}(\mathrm{II})$ and $\mathrm{Zn}(\mathrm{II})$ ions detoxification from waste water using unmodified and EDTA-modified maize husk. Electron J Biotechnol 10: 536-548.

5. Diniz V, Volesky B (2005) Biosorption of La, Eu and Yb using Sargassum biomass. Water Res 39: 239-247.

6. Drake LR, Lin S, Rayson GD (1995) Chemical modification and metal binding studies of Datura innoxia. Environ Sci Technol 30: 110-114.

7. Gardea-Torresdey JL, Arteaga S, Tiemann KJ, Chinaelli R, Pingatore N, et al. (2001) Absorption of Copper(II) by Creosote Bush (Larrea tridentata): use of atomic and x-ray absorption spectroscopy. Environ Toxicol Chem 20: 2572 2579 .

8. Lin S, Drake LR, Rayson GD (1996) Applications of frontal affinity chromatography to the study of interactions between metal ions and a complex biomaterial. Anal Chem 68: 4087-4093.

9. Drake LR, Hensman CE, Lin S, Rayson GD, Jackson PJ (1997) Characterization of metal ion binding sites on Datura innoxia by using lanthanide ion probe spectroscopy. Appl Spectrosc 51: 1476-1483.

10. Basha S, Jha B (2008) Estimation of isotherm parameters for biosorption of $\mathrm{Cd}(\mathrm{II})$ and $\mathrm{Pb}(\mathrm{II})$ onto brown seaweed, Lobophora variegate. J Chem Eng Data 53: 449-455.

11. Benhammou A, Yaacoubi A, Nibou L, Tanouti B (2005) Adsorption of metal ions onto Moroccan stevensite: kinetic and isotherm studies. J Colloid Interface Sci 282: 320-326.

12. Babarinde NA, Oyesiku OO, Dairo OF (2007) Isotherm and thermodynamic studies of the biosorption of copper (II) ions by Erythrodontium barteri. Int $\mathrm{J}$ Phys Sci 2: 300-304.

13. Sawalha MF, Peralta-Videa JR, Romero-González J, Duarte-Gardea M, Gardea-Torresdey JL (2007) Thermodynamic and isotherm studies of the biosorption of $\mathrm{Cu}(\mathrm{II}), \mathrm{Pb}(\mathrm{II})$, and $\mathrm{Zn}(\mathrm{II})$ by leaves of saltbush (Atriplex canescens). J Chem Thermodyn 39: 488-492.

14. Sawalha MF, Peralta-Videa JR, Romero-Gonzalez J, Gardea-Torresdey
$\mathrm{JL}$ (2006) Biosorption of $\mathrm{Cd}(\mathrm{II}), \mathrm{Cr}(\mathrm{III})$, and $\mathrm{Cr}(\mathrm{VI})$ by Saltbush (Atriplex canescens) biomass: thermodynamic and isotherm studies. J Colloid Interface Sci 300: 100-104

15. Serna DD, Moore JL, Rayson GD (2010) Site-specific Eu(III) binding affinities to a Datura innoxia biosorbent. J Hazard Mater 173: 409-414

16. Sawalha MF, Peralta-Videa JR, Duarte-Gardea M, Gardea-Torresdey JL (2008) Removal of copper, lead, and zinc from contaminated water by saltbush biomass: analysis of the optimum binding, stripping, and binding mechanism. Bioresour Technol 99: 4438-4444.

17. Moore JL, Rayson GD (2013) Thermodynamic parameters for Eu(III) Binding to Datura innoxia root material. Biometals 26: 755-762.

18. Bertoni FA, Medeot AC, Gonzalez JC, Sala LF, Bellu SE (2015) Application of green seaweed biomass for moVI sorption from contaminated waters Kinetic, thermodynamic and continuous sorption studies. J Colloid Interface Sci 446: 122-132.

19. Drake LR, Rayson GD (1996) Plant-derived materials for metal ion-selective binding and preconcentration. Anal Chem 68: 22A-27A.

20. Williams PA, Rayson GD (2003) Simultaneous multi-element detection of metal ions bound to a Datura innoxia material. J Hazard Mater 99: 277-285.

21. Koopal LK, Vos CH (1993) Adsorption on heterogeneous surfaces. Calculation of the adsorption energy distribution function or the affinity spectrum. LANGMUIR 9: 2593-2605.

22. Lehto J (2009) Americium in the finnish environment. Boreal Environ Res 14: $427-437$

23. Bieerkens J, Simkiss K (1990) The use of chemical analogues such as Eu/Am in ecotoxicological studies. Funct Ecol 4: 445-447.

24. Kaushik P, Goyal P (2008) In vitro evaluation of Datura innoxia (thorn-apple) for potential antibacterial activity. Indian J Microbiol 48: 353-357.

25. Nakajima A, Sakaguchi T (1990) Recovery and removal of uranium by using plant wastes. Biomass 21: 55-63.

26. Gracés JL, Mas F, Puy J (2004) Affinity distribution functions in multicomponen heterogeneous adsorption. Analytical inversion of isotherms to obtain affinity spectra. J Chem Phys 120: 9266-9276.

27. Gracés JL, Mas F, Puy J (2006) Conditional equilibrium constants in multicomponent heterogeneous adsorption: the conditional affinity spectrum. J Chem Phys 124: 044710

28. Černík M, Borkovec M, Westall JC (1995) Regularized least-squares methods for the calculation of discrete and continuous affinity distributions fo heterogeneous sorbents. Environ Sci Technol 29: 413-425.

29. Sips R (1948) On the structure of a catalyst surface. J Chem Phys 16: 490

\section{Acknowledgements}

The authors gratefully acknowledge the financial support of $\mathrm{RE}$ by Maximizing Access to Research Careers (MARC, NIH \#5T34GM007667-37). Los Alamos National Laboratory and the US Department of Energy is also acknowledged for the IRIS ICP spectrometer. The authors wish to also acknowledge the financial support of the National Institutes of Health through the MBRS-RISE program (\#R25GM061222) and the National Science Foundation under a NSF Graduate Research Fellowship (JLM).The authors gratefully acknowledge the financial support of RE by Maximizing Access to Research Careers (MARC, NIH \#5T34GM007667-37). Los Alamos National Laboratory and the US Department of Energy is also acknowledged for the IRIS ICP spectrometer. The authors wish to also acknowledge the financial support of the National Institutes of Health through the MBRS-RISE program (\#R25GM061222) and the National Science Foundation under a NSF Graduate Research Fellowship (JLM).. 